\title{
Assessment of the Healthy Lifestyle Behaviors and Associated Factors among First-Year Medical Students in Northern Cyprus
}

\author{
Gulifeiya Abuduxike (D), Ozen Aşut (D) \\ Department of Public Health, Near East University Faculty of Medicine, Nicosia, Northern Cyprus
}

ORCID iDs of the authors: G.A. 0000-0002-9798-7459; 0.A. 0000-0002-9604-4037.

Cite this article as: Abuduxike G, Aşut $O$. Assessment of the healthy lifestyle behaviors and associated factors among first-year medical students in Northern Cyprus. Cyprus J Med Sci. 2021; 6(3): 192-200.

\section{BACKGROUND/AIMS}

Health professionals play crucial roles in promoting healthy lifestyles to reduce the burden of noncommunicable diseases worldwide. The aim of the study was to assess the healthy lifestyle behaviors of the first-year medical students in Northern Cyprus and explore the related factors that influence their behaviors.

\section{MATERIAL and METHODS}

This was a cross-sectional study using a self-administrated questionnaire to collect information from 345 first-year medical students with a response rate of $88 \%$. A composite healthy lifestyle index was constructed as an outcome measurement of healthy lifestyles based on the eight lifestyle factors, namely, sleeping hours, diet, physical activity, body-mass index, sun protection, using a seatbelt, smoking, and alcohol intake.

\section{RESULTS}

Of all, $49.3 \%$ of the students were female and the mean age of the participants was $18.9 \pm 1.28$ years. About $59 \%$ of the students had unhealthy lifestyles, with high prevalence in all subfactors: smoking (47.5\%), inadequate diet (49.4\%), physical inactivity (45.8\%), insufficient sleep (29.4\%), no sunlight protection (77.4\%), no seat belt while driving (42\%), alcohol intake (38.2\%), and abnormal body-mass index (31.2\%). The boys were significantly more prone to risky behaviors than girls. Having negative perceptions of own health (OR $=$ 2.2; confidence interval [Cl]: 1.26-3.86) and body image ( $\mathrm{OR}=1.9 ; \mathrm{Cl}$ : 1.22-3.22) were positively associated with having unhealthy lifestyles.

\section{CONCLUSION}

Unhealthy behaviors were prevalent among the first-year medical students, and males were at higher risks. These findings highlighted the needs to develop gender-specific healthy lifestyle counseling programs into the first-year medical curriculum, integrated with sexual education and family planning components.

Keywords: Healthy lifestyles, risk factors, medical students, Northern Cyprus

\section{INTRODUCTION}

Noncommunicable diseases (NCDs), such as cardiovascular diseases, diabetes, cancers, mental disorders, and respiratory diseases, have become the leading causes of deaths globally. NCDs were responsible for 38 million deaths in 2012 , and it was projected to increase to 52 million by $20300^{1,2}$ The leading behavioral health risks that underlie these deaths are high blood pressure (responsible for $13 \%$ of global deaths), tobacco use ( $9 \%$ ), insufficient physical activity (6\%), overweight and obesity (5\%), alcohol use (5.9\%), unsafe sex (5\%), insufficient sleep, and traffic-related accidents. ${ }^{1,3-6}$ It was estimated that promoting and adopting a healthy lifestyle among people and reducing all these risks would reduce the deaths and disability-adjusted life years lost by three-quarters and could increase the global life expectancy by almost 10 years. $3,5,7-9$

According to the World Health Organization (WHO), a healthy lifestyle is a way of living to lower the risk of being seriously ill and prolong life expectancy with an improved quality of life (QoL). ${ }^{10}$ Health professionals can play a key role in advising and educating patients about the benefits of healthy lifestyle behaviors to prevent major lifestyle diseases. ${ }^{8, l}$ In 
order to effectively promote a healthy lifestyle to their patients and its' impact on QoL, it is crucial for medical students, doctors, and physicians have positive attitudes and practice of healthy behaviors."I3

Several studies conducted among the medical students in the US, Turkey, Netherlands, Germany, Australia, and Colombian have shown positive associations between practicing healthy behaviors such as having adequate physical activities, eating regularly, and having a normal body mass index (BMI) with higher confidence and willingness in promoting and counseling their patients about healthy living. ${ }^{11,12,14-17}$ Moreover, studies also suggested that encouraging healthy lifestyle among medical students could maintain their own health as individuals and, consequently, contribute more effectively and efficiently to the healthcare system in the future. ${ }^{11,12,18}$ As future physicians, medical students are expected to have greater knowledge and positive attitude toward healthy behaviors compare to nonmedical students. They are also expected to have better understanding of the long-term health consequences of smoking, drinking alcohol, inadequate diet, and other unhealthy habits. However, there is no evidence to indicate that they have a better practice of healthy habits even though they have greater knowledge compared to their counterparts. 19,20

A number of studies have demonstrated that medical students tend to develop unhealthy behaviors as coping strategies due to the high demand for medical training and a high risk of burnout and stress. $11,15,18,21,22$ Numerous studies have indicated that many medical students experience changes in their life patterns and develop unhealthy dietary habits along with sleep deprivation during the medical school years, particularly in the first year. As a result, the prevalence of smoking, alcohol intake,

\section{Main Points}

- Noncommunicable diseases (NCDs) have become the leading causes of deaths globally. A healthy lifestyle is a way of living to lower the risk of being seriously ill and prolong life expectancy with an improved quality of life (QoL).

- Health professionals can play a key role in promoting and educating patients about the benefits of healthy lifestyle behaviors to prevent major NCDs. In order to effectively promote a healthy lifestyle to their patients, it is crucial for medical students, doctors, and physicians have positive attitudes and practice of healthy behaviors.

- This study assessed the practice of healthy lifestyle behaviors of the first-year medical students and to explore the associated factors that influencing their behaviors using a composite healthy lifestyle index which was constructed based on eight lifestyle factors.

- The findings revealed that unhealthy behaviors were prevalent among the first-year medical students, and males were at higher risks. The results also highlighted that medical students have inadequate knowledge and lack of positive attitudes toward healthy behaviors. It is strongly recommend to develop gender-specific healthy lifestyle counseling programs to be integrated into the medical curriculum during the first year. physical inactivity, irregular diet, obesity, and overweight among medical students were as high as among their peers in other faculties or in general populations. ${ }^{20-26}$

These studies have revealed that lack of time, inadequate management of time and stress, lack of sleep, and other mental health problems such as depression and fatigue were the main reasons for medical students could not have time to involve in other recreational activities and to follow proper dietary habits. ${ }^{19,27,28}$ There are several studies conducted among Turkish medical students that have revealed the high prevalence of hazardous health behaviors. ${ }^{29-31}$ For instance, one of these studies revealed that the prevalence of smokers was $24.8 \%$, alcohol intake was $19.8 \%$, physical inactivity was $64 \%$, insufficient sleep was $13 \%$, more than $50 \%$ of the participants did not have proper dietary intakes, $26.5 \%$ of them were overweight or obese, and about $9 \%$ did not use condoms. Male students were shown to have higher risks compared to females in all aspects. $^{30}$

As the health habits of medical students may influence their attitude in counseling their patients about healthy living and preventive interventions, some studies have focused on developing interventions and specific strategies to encourage medical students to adopt and keep up healthy behaviors. ${ }^{12,32,33}$ Various educational interventions were developed to improve the knowledge level regarding healthy behaviors, and promoting self-care among medical students have shown significant effectiveness, particularly among the first-year students. ${ }^{13,18,34,35}$ This is a well-researched area around the world, yet, there is no single research conducted in Turkish Republic of Northern Cyprus in this specific arena. Thus, in this study, we sought to examine the practice of healthy lifestyle behaviors of the firstyear medical students from one of the biggest universities in Northern Cyprus and to explore the related factors that influencing their behaviors.

\section{MATERIAL and METHODS Study Design}

A cross-sectional study was conducted among the first-year medical students, who enrolled in 2016. Written informed consent was taken, and detailed information was provided to the students before the data collection.

\section{Study Participants and Sampling}

All first-year medical students from the Faculty of Medicine were invited to take part in the study. The self-administrated questionnaires were asked to answer the questions in the classroom after completing the public health courses. Out of 393 students, 345 students have responded to the questionnaires with a response rate of $88 \%$.

\section{Study Tools}

A self-administrated questionnaire was developed by the researchers based on the extensive review of the literature. The questionnaire has consisted of 50 questions with three main components. The first part included II questions on sociodemographic characteristics, including nationality, income level, country of origin, marital status, and self-reported height and weight. BMI was calculated using the formula weight/ hight $^{2}$ $\left(\mathrm{kg} \mathrm{m}^{-2}\right)$ and classified according to the WHO international BMl cutoff points. ${ }^{3}$ The second part had eight questions on the general health status of the participants, including self- 
TABLE I. Health Factors of the Combined Lifestyle Score of the Participants ( $n=345)$

\begin{tabular}{|c|c|c|c|}
\hline Healthy lifestyle score factor & Score & Description & Percentage \\
\hline \multirow[t]{2}{*}{ Smoking } & 0 & Yes (former or current smoker) & 47.5 \\
\hline & I & No (never smoke) & 52.5 \\
\hline Dietary intake & 0 & No (inadequate based on the given definition) & 49.4 \\
\hline \multirow[t]{2}{*}{ Physical activities } & 0 & No & 45.8 \\
\hline & I & Yes (based on the given definition) & 54.2 \\
\hline Sleeping hours & 0 & No (inadequate sleeping hours: $<7$ or $>9$ hours) & 29.4 \\
\hline Sunlight protection & 1 & Yes (used sunscreen, hat, sunglasses, and covering clothes) & 22.6 \\
\hline \multirow[t]{2}{*}{ Wearing a seatbelt } & 0 & No (did not use) & 42.0 \\
\hline & 1 & Yes (always use) & 58.0 \\
\hline \multirow[t]{2}{*}{ Alcohol intake } & 0 & Yes & 38.6 \\
\hline & I & No (never consumed alcohol) & 61.4 \\
\hline Body mass index & 0 & Not normal BMI $\left(\leq 18.4 \mathrm{~kg} \mathrm{~m}^{-2}\right.$ and $\left.\geq 25 \mathrm{~kg} \mathrm{~m}^{-2}\right)$ & 31.2 \\
\hline
\end{tabular}

perceived body image, medical history, and self-perception of being healthy. The third part consisted of 31 questions related to healthy lifestyle behaviors such as smoking, alcohol intake, sleep patterns, using a seatbelt, sun protection, stress, use of family planning (FP) methods, and using protective methods to prevent Sexually Transmitted Infections (STIs). Also, there were some questions to understand the participant's knowledge level and perceptions of these behaviors.

\section{Definition of the Eight Lifestyle Factors and the Composite Healthy Lifestyle Index}

A composite healthy lifestyle index was constructed based on the eight modifiable lifestyle factors and participants received a score (healthy $=1$ and unhealthy $=0$ ) for the responses given for each behavior based on the evidence and standard recommendations $^{36}$ (Table I): (I) Having a healthy diet was defined as "the intake of energy and nutrients complying with the needs and features of the body of an individual ${ }^{\prime \prime}$; Participants were asked "according to this definition, do you think your diet is sufficient and balanced?" with the answers of "yes, I do" and "No, I don't think so." (2) Participants were considered physically active if they do at least 150 minutes of moderate-intensity aerobic physical activities throughout the week in the last seven days ${ }^{37}$; (3) Having adequate sleeping hours was measured according to the international standards for young adults (18-25 years), which is 7-9 hours per day. ${ }^{38}$ This age group was used as a reference as the mean age of the study participants was $18.9 \pm 1.28$ years; participants were asked "how many hours do they sleep every day" and the scores were given based on the answers ( $>9$ and $<7$ hours were considered inadequate); (4) Sun protection was measured if used any method to protect from sunlight to avoid the harmful effects of excessive sun exposure; (5) Participants were asked if they always wear a seat belt while driving (or in the vehicle) with the answers of "Yes" and "Never"; (6) Smoking status was assessed using a question "Did you ever smoke or do you currently smoke?" and the answers were categorized as "Yes" and "No." (7) Similar question was used to assess alcohol consumption with the answers of "Yes" and "No"; (8) BMl categories: having a BMl in a range of $18.5-24.9 \mathrm{~kg} \mathrm{~m}^{-2}$ was considered having a "normal weight." The participants with a BMI in the categories of underweight $\left(<18.5 \mathrm{~kg} \mathrm{~m}^{-2}\right.$ ), overweight (25.0$\left.29.9 \mathrm{~kg} \mathrm{~m}^{-2}\right)$, and obese $\left(>30 \mathrm{~kg} \mathrm{~m}^{-2}\right)$ were classified as having a "not normal weight." The composite healthy lifestyle index was generated by summing up the binary score for each of the eight factors. The value of the healthy lifestyle index was dichotomized, which ranged from 0 (least healthy) to 8 (healthiest). Based on extensive review of literature and experts' opinion, we considered participants with five and above scores to have healthy lifestyles as the scores classified into "unhealthy" (0-4) and "healthy" ${ }^{\prime 5-8}$ categories. $^{36,39}$

A pretest for the questionnaires was conducted among 30 students from other faculties prior to the research to improve the clarity, adequacy of the answers and the time spent in completing the questions. Minor revisions were done based on the pretest results.

\section{Statistical Analysis}

The data analysis was carried out using Statistical Package for the Social Sciences (SPSS) version 23.0 (IBM SPSS Corp.; Armonk, NY, USA). Descriptive statistics including frequency, percentage, mean, and standard deviation were done to describe the characteristics of the study sample. Distribution of participants' sociodemographic characteristics by the outcome variable (healthy and unhealthy lifestyle) was analyzed using the Chi-square statistics, with a significance level set at $P<.05$. All variables having $P<.05$ were entered in the final model of multivariate logistic regression analysis to identify factors associated with the healthy lifestyle status. As a result, adjusted odds' ratios and $95 \%$ confidence intervals $(\mathrm{Cls})$ were presented with the $P$ value set at $<.05$.

\section{Ethical Approval}

The ethical approval was obtained from the Ethical Committee of the Near East University for the study protocol with a project number of 2016/39-324. The questionnaires were anonymous, and informed consent was obtained from all individual participants. All procedures performed in this study were in accordance with the ethical standards of the institutional and/or national research committee and with the 1964 Helsinki 
TABLE 2. Sociodemographic Characteristics in Relation to the Lifestyle Status of the Participants ( $n=345)$

\begin{tabular}{|c|c|c|c|c|c|c|c|}
\hline & \multicolumn{2}{|c|}{ Total } & \multicolumn{2}{|c|}{ Unhealthy lifestyle } & \multicolumn{2}{|c|}{ Healthy lifestyle } & \multirow[b]{2}{*}{$P$-Value } \\
\hline & $N$ & $\%$ & $\mathbf{n}$ & $\%$ & $\mathrm{n}$ & $\%$ & \\
\hline \multicolumn{8}{|l|}{ Age Group (Years) } \\
\hline $20-25$ & 76 & 22.0 & 47 & 61.8 & 29 & 38.2 & \\
\hline \multicolumn{8}{|l|}{ Gender } \\
\hline Male & 175 & 50.7 & 110 & 62.9 & 65 & 37.1 & .099 \\
\hline Turkish & 204 & 59.1 & 116 & 56.9 & 88 & 43.1 & .444 \\
\hline English & $|4|$ & 40.9 & 86 & 61.0 & 55 & 39.0 & \\
\hline \multicolumn{8}{|l|}{ Nationality } \\
\hline Turkish & 204 & 60.0 & $\| 8$ & 58.7 & 83 & 41.3 & .353 \\
\hline Turkish Cypriots & 24 & 7.2 & $\|$ & 45.8 & 13 & 54.2 & \\
\hline Others & 110 & 32.8 & 68 & 61.8 & 42 & 38.2 & \\
\hline \multicolumn{8}{|l|}{ Income Level } \\
\hline Yes & 37 & 10.8 & 22 & 59.5 & 15 & 40.5 & .893 \\
\hline No & 30 & 89.2 & 179 & 58.3 & 128 & 41.7 & \\
\hline
\end{tabular}

declaration and its later amendments or comparable ethical standards, as revised in 2000.

\section{RESULTS \\ Distributions of the Healthy Lifestyle Behaviors among Study Participants}

Out of the total 345 respondents, about half (49.3\%) of them were female. The mean age of the participants was $18.9 \pm$ 1.28 years. As presented in Table I, about $58.6 \%$ of the participants were classified as having unhealthy lifestyles (score 0-4) based on the composite lifestyle index. The proportions of each individual risk factor were also shown to be high among study participants.

\section{Sociodemographic Characteristics and the Lifestyle Status of the Participants}

As shown in Table 2, the majority (78\%) of the participants were in their late adolescence. More than half of the participants were originally from Turkey and $32.8 \%$ of them were mainly from Middle Eastern countries, while only $7.2 \%$ of them were originally from Northern Cyprus. Of all, $10.8 \%$ of them reported having some form of chronic diseases. Although the proportion of boys who had an unhealthy lifestyle was notably higher than girls, however, the difference in gender was not statistically significant. Similarly, all other sociodemographic characteristics did not demonstrate any statistically significant relationship with their lifestyle status.

\section{Participants' Perceptions and Knowledge in Relation with the Lifestyle Status}

The relationships between participants' perception of their own health status, self-body image, and healthy lifestyle behaviors were presented in Table 3. There were significant differences between BMI categories and lifestyle status of the participants, while obese and overweight students tend to have a higher tendency of having unhealthy lifestyles compared to the students with a normal BMI. A notable significant difference was observed between students' self-perception of health, where $74.3 \%$ of students who considered themselves not healthy were actually having unhealthy lifestyles. On the other hand, the majority of the students who perceived own body as "not ideal" were more likely to have unhealthy lifestyles than others. A great number of students who often skip any meals were shown to have a significantly higher tendency of unhealthy lifestyles compared to the ones who did not. A significant difference was observed among students who did not have enough sleep with a higher tendency of having unhealthy lifestyles than those who have adequate sleep daily.

The participants were asked a question to examine their perception of being healthy ("What do you do to be healthy?"). Almost half of the participants have indicated that healthy diet, no smoking, no alcohol, good sleep, regular exercise, avoid excessive sunlight, no stress (28.4\%), and using a seat belt while driving are the healthy behaviors to have in order to be healthy. When asked about the health benefits of physical activities, about $85 \%$ of them mentioned that it is helpful in controlling weight, $73 \%$ of them indicated that it prevents heart diseases, diabetes, and hypertension, $78 \%$ of the participants said it provides psychological well-being, and about $30 \%$ mentioned that it will help to protect from cancers, bone fractures, and strengthens one's memory.

With regard to the questions on sleep quality, 39.5\% reported having sleeping problems during the last month. Among these, $32.6 \%$ had difficulty in falling asleep, about $40 \%$ felt tired upon waking up from sleep, while $20.6 \%$ reported having excessive sleep. About the harmful consequences of the excessive sunlight exposure, the majority were aware of the negative health effects such as skin cancer $(74.3 \%)$, eye problems $(57.4 \%)$, aging skin $(67.2 \%)$, and sunburn (60.7\%). However, only $22.6 \%$ of the respondents have used some methods to protect from sunlight. About $40 \%$ of the participants have reported skipping any one of the three meals in a day and among these, $44 \%$ of them skipped breakfast, $23.3 \%$ skipped lunch, while $19.4 \%$ of them skipped dinner. 
TABLE 3. Health Perceptions and Daily Habits in Relation with Lifestyle Status of the Participants $(n=345)$

\begin{tabular}{|c|c|c|c|c|c|c|c|}
\hline & \multicolumn{2}{|c|}{ Total } & \multicolumn{2}{|c|}{ Unhealthy lifestyle } & \multicolumn{2}{|c|}{ Healthy lifestyle } & \multirow[b]{2}{*}{$P$-Value } \\
\hline & $\mathrm{N}$ & $\%$ & n & $\%$ & $\mathbf{n}$ & $\%$ & \\
\hline \multicolumn{8}{|l|}{ Body Mass Index } \\
\hline Overweight & 49 & 18.2 & 41 & 83.7 & 8 & 16.3 & \\
\hline Normal & 185 & 68.8 & 74 & 40.0 & III & 60.0 & \\
\hline Underweight & 21 & 7.8 & 17 & 81.0 & 4 & 19.0 & \\
\hline Unhealthy & 105 & 31.3 & 78 & 74.3 & 27 & 25.7 & \\
\hline \multicolumn{8}{|l|}{ Self-Body Image } \\
\hline Ideal & 172 & 50.0 & 87 & 50.6 & 85 & 49.4 & $.003^{*}$ \\
\hline Not Ideal & 172 & 50.0 & $\| 4$ & 66.3 & 58 & 33.7 & \\
\hline \multicolumn{8}{|c|}{ Skip Any One of Three Meals in a Day } \\
\hline Yes & 204 & 59.8 & 130 & 63.7 & 74 & 36.3 & $.014^{*}$ \\
\hline Yes & 203 & 59.9 & 124 & 62.1 & 79 & 38.9 & .340 \\
\hline No & 136 & 40.1 & 76 & 55.9 & 60 & 44.1 & \\
\hline
\end{tabular}

\section{TABLE 4. Distribution of Healthy Lifestyle Behaviors by Sex $(n=345)$}

\begin{tabular}{|c|c|c|c|c|c|c|c|}
\hline & \multicolumn{2}{|c|}{ Total } & \multicolumn{2}{|c|}{ Female } & \multicolumn{2}{|c|}{ Male } & \multirow[b]{2}{*}{$P$-Value } \\
\hline & $N$ & $\%$ & 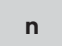 & $\%$ & $\mathbf{n}$ & $\%$ & \\
\hline \multicolumn{8}{|l|}{ Body Mass Index } \\
\hline Overweight & 49 & 18.2 & 9 & 18.4 & 40 & 81.6 & \\
\hline Normal & 185 & 68.8 & 96 & 51.9 & 89 & 48.1 & \\
\hline Underweight & 21 & 7.8 & 16 & 76.2 & 5 & 23.8 & \\
\hline \multicolumn{8}{|l|}{ Smoking } \\
\hline \multicolumn{8}{|l|}{ Dietary Intake } \\
\hline Yes & 172 & 50.6 & 87 & 50.6 & 85 & 49.4 & .828 \\
\hline No & 168 & 49.4 & 83 & 49.4 & 85 & 50.6 & \\
\hline \multicolumn{8}{|c|}{ Physical Activities } \\
\hline Yes & $|8|$ & 54.2 & 91 & 50.3 & 90 & 49.7 & .819 \\
\hline No & 153 & 45.8 & 75 & 49.0 & 78 & 51.0 & \\
\hline Yes & 77 & 22.6 & 27 & 35.1 & 50 & 64.9 & $.003^{*}$ \\
\hline No & 263 & 77.4 & 142 & 54.0 & 121 & 46.0 & \\
\hline \multicolumn{8}{|l|}{ Alcohol Intake } \\
\hline Yes & $|3|$ & 38.6 & 59 & 45.0 & 72 & 55.0 & .187 \\
\hline No & 208 & 61.4 & 109 & 52.4 & 99 & 47.6 & \\
\hline \multicolumn{8}{|l|}{ Using a Seatbelt } \\
\hline Yes & 193 & 58.0 & 94 & 48.7 & 99 & 51.3 & .815 \\
\hline No & 140 & 42.0 & 70 & 50.0 & 70 & 50.0 & \\
\hline \multicolumn{8}{|c|}{ Have Had Sexual Experiences $(n=323)$} \\
\hline Yes & 47 & 14.6 & 7 & 14.9 & 40 & 85.1 & $.000^{*}$ \\
\hline No & 276 & 85.4 & 154 & 55.8 & 122 & 44.2 & \\
\hline
\end{tabular}

\section{Distribution of the Individual Health Behaviors by Gender}

There were significant differences between genders with regard to the $\mathrm{BMI}$, smoking status, sexual experiences, and protection from the excessive sunlight (Table 4).
Male students were more likely to be obese and overweight than girls $(78.6 \%$ vs $21.4, P<.001)$. Similarly, the high-risk behaviors such as smoking and having sexual relationships were significantly prevalent among boys compared to girls (58\% vs 


\begin{tabular}{|c|c|c|c|c|c|c|c|}
\hline & B & SE & Wald & $P$-Value & $\operatorname{Exp}(B)$ & \multicolumn{2}{|c|}{$95 \% \mathrm{Cl}$} \\
\hline Self-description on body image (not ideal/ideal) & 0.685 & 0.248 & 7.638 & .006 & 1.983 & 1.220 & 3.223 \\
\hline Having a sexual experience (no/yes) & -0.321 & 0.383 & 0.699 & .403 & 0.726 & 0.342 & 1.539 \\
\hline Self-perception of having enough sleep (no/yes) & 0.477 & 0.270 & 3.131 & .077 & 1.611 & 0.950 & 2.733 \\
\hline Having stress in a daily life (no/yes) & -0.012 & 0.260 & 0.002 & .962 & 0.988 & 0.594 & 1.642 \\
\hline Age & 0.086 & 0.102 & 0.709 & .962 & 0.988 & 0.594 & 1.642 \\
\hline Constant & -1.783 & 2.044 & 0.761 & .383 & 0.168 & & \\
\hline
\end{tabular}

$42 \%$ and $85.1 \%$ vs $14.9 \%, P<.001$, respectively). Interestingly, the boys also have a higher tendency to protect from excessive sunlight compare to the girls $(64.9 \%$ vs $35.1 \%, P<.001)$. There were no significant gender differences between other behaviors such as alcohol intake, physical activity, sleeping hours, dietary intake, and usage of seatbelt while driving.

About 15\% out of all participants has reported having sexual relationship previously, and there was a significant difference between age groups as the older students have a higher tendency to have sexual relationships than the younger ones $(P<$ $.001)$. A significant number of students who had sexual experience had never used a condom $(75.7 \%, P<.001)$. An evident difference was detected between lifestyle status and sexual experience, where the students with unhealthy lifestyles have a higher tendency of having sexual experiences (17.6\%) compared to the ones who have healthy lifestyles, although it was not statistically significant $(P>.05)$. The participants' knowledge on the prevention of STls has shown a significant difference in their sexual experience $(P<.01)$. However, participants' knowledge regarding FP and its methods, knowledge about emergency contraception (EC), and types of EC did not affect their lifestyle behaviors. The results of the logistic regression to examine the predicting factors associated with lifestyle status of the participants adjusted for age and gender were shown in Table 5. It presented that the odds of having unhealthy lifestyles among the students who perceived their body "not ideal" and "not healthy" were 1.98 (95\% Cl: I.220-3.223) and 2.21 (95\% Cl: 1.264-3.863) times higher than the students who perceived their body "ideal" and "healthy," respectively, which were statistically significant $(P=.006$ and .005).

\section{DISCUSSION}

The current study is the first of its kind conducted in Northern Cyprus, which examined the healthy lifestyle behaviors and associated factors among the first-year medical students from a university. The investigation of the lifestyle behaviors among medical students is essential to provide a foundation for the development of the evidence-based interventions or curriculums for helping them to develop and adopt healthy lifestyles. Subsequently, it will increase the willingness and attitude to promote healthy lifestyles to their patients in the future. In the present study, about 59\% of students had "unhealthy lifestyles," which was scored based on the combination of eight subfactors of behaviors. A considerably higher proportion of male students has unhealthy lifestyles compared to girls; nevertheless, this difference was not statically significant. However, a study from Pakistan has found that girls tend to have healthier lifestyle habits and diet practices compared to boys, which was statistically significant. ${ }^{40}$

The prevalence of smoking was $47.5 \%$ among all, where smoking among boys was detected to be more prevalent (58\%) compared to girls (42\%). The statistical significance in gender was consistent with the study conducted among the Turkish medical students from Erciyes University, although the overall and gender-specific prevalence in our study were much higher compared to the Turkish medical students in other studies. ${ }^{30,31,41}$ This might be due to the age composition of our sample as the majority (78\%) were adolescents and youth, and the smoking prevalence was reported to be as high as $55 \%$ among Cypriot adolescents, ${ }^{42}$ where they might be experiencing the transitional period in their life and most of their behavior was affected by their peers and friends. The sex difference and high prevalence of smoking were consistent with a study conducted among the medical students in Ethiopia, ${ }^{43}$ however, was in contrast to a study conducted in Greek among health science students $(37.6 \%)^{14}$

There were consistencies in our results with other studies in terms of alcohol intake (38.6\%), ${ }^{30,31,43}$ physical inactivity $(45.8 \%),{ }^{14,30,44,45}$ inadequate sleeping hours $(29.4 \%){ }^{30}$ and not using a seat belt while driving (42\%). ${ }^{30,46}$ Among these, the prevalence of not using seat belt while driving was not significantly different between genders in our study, which was demonstrated a contrast with another study result (boys 55\% vs girls $49 \%$ ), and there was also a significant difference among the first-year medical students compared to the last year students. ${ }^{30}$ The prevalence of physical inactivity was higher compared to most of the 2l European countries in a study conducted among Young Europeans; however, it was in line with several European countries such as Greece, Portugal, and Spain. ${ }^{45}$

In the current study, about half (49.4\%) of the students did not have adequate dietary intake, and the trend was similar to both genders. This was consistent with a study, which reported that $55 \%$ of male students have consumed fast food every day/frequently. ${ }^{30}$ Moreover, our study results demonstrated that about $60 \%$ of the participants have always skipped one of the three meals, and those who often skipped meals have a significantly higher tendency of having unhealthy lifestyles than those who did not. These findings were consistent with the study from Pakistan, and the main reason for medical students for skipping meals was "lack of time." 30,40

One of the important subcategories in the composite lifestyle index was $\mathrm{BMl}$ of the students. Our study revealed that 
students with a "not healthy" BMI were $31.2 \%$, including obese, overweight, and underweight which were $5.2 \%, 18.2 \%$, and $7.8 \%$, respectively. Moreover, there was a significant difference between genders as more boys tend to be obese and overweight than girls, whereas more girls tend to be underweight compared to boys. The obesity and overweight prevalence among our study sample was slightly higher than several studies conducted among medical students $26,41,47,48$; however, it was much lower than the prevalence among the first-year students from studies conducted in Turkey and Australia. ${ }^{30,49}$

The significant difference in BMl between genders was seen in most of these studies, which was similar to ours. Primarily, this trend can be explained by the high prevalence of sedentary lifestyle, physical inactivity, poor eating habits, and lack of adequate sleep among medical students and, in general, girls tend to be more cautious about their appearances and make efforts to practice healthier behaviors, ${ }^{49-51}$ which might be attributed to their low BMl compared to boys. This was supported by the significant positive correlation found in our study between the self-perception of "not ideal" body image and unhealthy lifestyle among the students. More male students perceived their body is "not ideal" than girls, though this difference is not statistically significant. In our study, interestingly, more males perceived themselves as "healthy" compared to girls and this can be one of the reasons for boys not to spend too much effort to be healthy.

A notable proportion of students who considered themselves "not healthy" actually were having unhealthy lifestyles and more among boys. This positive relationship was statistically significant and consistent with a study conducted by Nacar et al. $^{30}$ All these evidence indicate that self-perception of body image and knowledge of being healthy to play an important role in one's behaviors and practice of healthy lifestyles. Hence, educating medical students regarding the risky behaviors and healthy body image, encouraging them to translate their knowledge into daily practice should be the essential component of the interventions or counseling program for the students.

Another important finding of this present study was the examination of the participants' sexual practices and knowledge of the FP and practices of using contraception methods. As most of our participants constituted of adolescents and youth, it will be important to examine their sexual health knowledge and practices to prevent risky sexual behaviors in the future. The prevalence of students who had sexual experiences in our study was lower compared to the prevalence of university students in Turkey. However, a significantly higher prevalence of students with sexual experience did not use condoms, and the low level of knowledge regarding contraception methods and prevention methods of STls should be given high attention among educators. Particularly, a comprehensive sexuality education on reproductive health and prevention of STIs should be provided for the first-year medical students, which should be the essential components of the first-year medical curriculum along with the healthy lifestyle education.

There are several limitations to the current study. First, as this is a cross-sectional study conducted among medical students from one university using a purposive sampling method, the results from this study cannot generate causal relationships between healthy lifestyle status and related fac- tors. Furthermore, it is also difficult to generalize the results to represent the entire population of the island. However, as the university is one of the biggest universities in Northern Cyprus and the total population of the island is about $300,000,{ }^{52}$ we could refer to this study as the first attempt to fill the gap in this area. Second, the data were collected based on the self-report of the students, which might lead to recall bias and underreporting of some sensitive behaviors, particularly related to sexual practices. Third, recognizing the sex differences in muscle mass, which is the limit of comparison of BMl between genders, can be one of the limitations of the study. Apart from the above limitations, the study results not only provide appealing insights regarding the prevalence of healthy behaviors among the first-year medical students and associated factors but also provide evidence to improve medical students' general health by modifying curriculums and counseling programs in the future.

In conclusion, the study results demonstrated that the majority of the first-year medical students have had unhealthy lifestyles. Those include the high prevalence of smoking, alcohol intake, physical inactivity, insufficient sleep, inadequate eating habits, and unsafe sexual practices among these students. It also highlighted the significant sex differences in most of the risky habits, where boys were more prone to have unhealthy lifestyle due to these risky habits. Moreover, the results revealed that medical students have insufficient knowledge and lack of positive attitudes toward healthy behaviors. This could eventually adversely influence their health-promoting practices in the future and willingness to consult their patients regarding healthy living. Hence, it is vital to develop gender-specific healthy lifestyle counseling programs to be a part of the medical curriculum during the first year. This study results can provide evidence to the local stakeholders, educators, and policymakers to modify the current curriculum with proposed amendments. Furthermore, a comprehensive sexuality education, including FP should be one of the compulsory subjects for the students at this stage.

Ethics Committee Approval: The ethical approval was obtained from the Ethical Committee of the Near East University for the study protocol with a project number of 2016/39-324.

Informed Consent: Written informed consent was obtained from all participants who participated in this study.

Peer-review: Externally peer-reviewed.

Author Contributions: Concept - G.A., O.A.; Design - G.A., O.A.; Supervision - G.A., O.A.; Resources - G.A., O.A.; Materials - G.A.; O.A.; Data Collection and/or Processing - G.A., O.A.; Analysis and/or Interpretation G.A., O.A.; Literature Search - G.A., O.A.; Writing Manuscript - G.A., O.A.; Critical Review - G.A., O.A.

Conflict of Interest: The authors have no conflicts of interest to declare.

Financial Disclosure: The authors declared that this study has received no financial support.

\section{REFERENCES}

I. WHO. Global Status Report on Noncommunicable Diseases 2014. Geneva: World Health Organization, 20l4. Available at http:/ / apps.who.int/iris/bitstream/handle/10665/1481|4/9789241564854_ eng.pdf; jsessionid=77832C88122D7CB5DD7073747B6IA3AC?sequ ence $=$. Accessed date: 6 September 2018. 
2. Patel $V$, Flisher AJ, Hetrick S, McGorry P. Mental health of young people: A global public-health challenge. Lancet. 2007;369(4):I302$13 \mid 3$.

3. WHO. Global Health Risks: Mortality and Burden of Disease Attributable to Selected Major Risks. Vol. 87. Bulletin of the World Health Organization. Geneva, Switzerland, 2009. Available at http:// www.who.int/healthinfo/global_burden_disease/GlobalHealth Risks_report_full.pdf?ua=I反ua=I. Accessed date: 3 September 2018.

4. WHO. World Health Statistics 2018-Monitoring Health for the SDG's (Sustainable Development Goals). Geneva, Switzerland: WHO, 2018.

5. Gore FM, Bloem PJN, Patton GC, et al. Global burden of disease in young people aged 10-24 years: A systematic analysis. Lancet. 2011;377(9783):2093-2102.

6. Moreno-Gómez C, Romaguera-Bosch D, Tauler-Riera P, et al. Clustering of lifestyle factors in Spanish university students: The relationship between smoking, alcohol consumption, physical activity and diet quality. Public Health Nutr. 2012;15(II):2131-2139.

7. Patton GC, Coff C, Sawyer SM, et al. Global patterns of mortality in young people: A systematic analysis of population health data. Lancet. 2009;374:88I-892.

8. WHO. Global Strategy on Diet, Physical Activity and Health: Eighth Plenary Meeting. Geneva, Switzerland: WHO, 2004. Available at http://apps.who.int/gb/ebwha/pdf_files/WHA57/A57_RI7-en. pdf. Accessed date: 3l August 2018.

9. Lopez AD, Mathers CD, Ezzati M, Jamison DT, Murray CJ. Global and regional burden of disease and risk factors, 200I: Systematic analysis of population health data. Lancet. 2006;367(9524):1747-1757.

10. WHO. Healthy Living: What is a Healthy Lifestyles? Copenhagen: World Health Organization, 1999. Available at http://apps. who.int/iris/bitstream/handle/10665/108180/EUR_ICP_LVNG_ 0l_07_02.pdf. Accessed date: 25 August 2018.

II. Duperly J, Lobelo F, Segura C, et al. The association between Colombian medical students' healthy personal habits and a positive attitude toward preventive counseling: Cross-sectional analyses. BMC Public Health. 2009;9:218.

12. Lobelo F, Duperly J, Frank E. Physical activity habits of doctors and medical students influence their counselling practices. Br J Sports Med. 2008;43(2):89-92.

13. Ayala EE, Winseman JS, Johnsen RD, Mason HRC. U.S. medical students who engage in self-care report less stress and higher quality of life. BMC Med Educ. 2018;18(I):9.

14. Papathanasiou G, Papandreou M, Galanos A, et al. Smoking and physical activity interrelations in health science students. Is smoking associated with physical inactivity in young adults? Hell J Cardiol. 2012;53:17-25.

15. van der Veer T, Frings-Dresen MHW, Sluiter JK. Health behaviors, care needs and attitudes towards self-prescription: A crosssectional survey among Dutch medical students. PLoS One. 20Il;6(II):e28038.

16. Peleias $M$, Tempski $P$, Paro HB, et al. Leisure time physical activity and quality of life in medical students: Results from a multicentre study. BMJ Open Sport Exerc Med. 2017;3(1):e000213.

17. Potgieter S. Wellness as a virtue in health sciences students: Are they practising what they preach? South Afr J Clin Nutr. 2015;28(4):152-153.

18. Ball S, Bax A. Self-care in medical education: Effectiveness of health-habits interventions for first-year medical students. Acad Med. 2002;77:911-917.

19. Shoukat R, Raza S, Shiekh RM, et al. Knowledge and practice of healthy lifestyle and dietary habits in medical and non-medical students of Karachi. J Pakistan Med Assoc. 2009;59(9):650-655.
20. Mokbel Alissa E, Alsawadi H, Zedan A, Alqarni D, Bakry M, Bin $\mathrm{HN}$. Attitude and practice of dietary and lifestyle habits among medical students in King Abdulaziz university, Saudi Arabia. Int $J$ Nutr Food Sci. 2015;4(6):650-655.

21. Hilger J, Loerbroks A, Diehl K. Eating behaviour of university students in Germany: Dietary intake, barriers to healthy eating and changes in eating behaviour since the time of matriculation. Appetite. 2017;109:100-107.

22. Majeed F. Association of BMl with diet and physical activity of female medical students at the university of Dammam, Kingdom of Saudi Arabia. J Taibah Univ Med Sci. 2015;10(2):188-196.

23. Odlaug BL, Lust $K$, Wimmelmann $C L$, et al. Prevalence and correlates of being overweight or obese in college. Psychiatry Res. 2015;227(I):58-64.

24. Kelly NR, Mazzeo SE, Bean MK. Systematic review of dietary interventions with college students: Directions for future research and practice. J Nutr Educ Behav. 2013;45(4):304-313.

25. Breitenbach Z, Raposa B, Szabó Z, et al. Examination of Hungarian college students' eating habits, physical activity and body composition. Eur J Integr Med. 2016;8:13-17.

26. Hamam FA, Eldalo AS, Alnofeie AA, Alghamdi WY, Almutairi SS, Badyan FS. The association of eating habits and lifestyle with overweight and obesity among health sciences students in Taif University. KSA J Taibah Univ Med Sci. 2017;12(3):249-260.

27. Terebessy A, Czeglédi E, Balla BC, Horváth F, Balázs P. Medical students' health behaviour and self-reported mental health status by their country of origin: A cross-sectional study. BMC Psychiatry. 2016;16(I):2018-2030.

28. Askarian $M$, Dehghani Z, Danaei $M, \vee$ akili $\bigvee$. Knowledge and practice of medical students on healthy lifestyle: A cross-sectional study in Shiraz. J Heal Sci Surveill Syst. 20I3;I(2):77-82.

29. Naçar M, Çetinkaya F, Baykan Z, Zararsiz G, Yilmazel G, Sağiroğlu $M$. Health related lifestyle behaviors among students at a vocational education center in Turkey. Health. 2015;7(II):15361544.

30. Nacar M, Cetinkaya F, Baykan Z, et al. Hazardous health behaviour among medical students: A study from Turkey. Asian Pacific J Cancer Prev J Cancer Prev. 2015;16(1617):7675-768l.

31. Akvardar $Y$, Demiral $Y$, Ergör $G$, et al. Substance use in a sample of Turkish medical students. Drug Alcohol Depend. 2003;72(2):117121.

32. Frank E, Tong E, Lobelo F, Carrera J, Duperly J. Physical activity levels and counseling practices of U.S. medical students. Med Sci Sports Exerc. 2008;40(3):413-421.

33. Cornuz J. Physicians' attitudes towards prevention: Importance of intervention-specific barriers and physicians' health habits. Fam Pract. 2000;17(6):535-540.

34. Sastre EA, Burke EE, Silverstein E, et al. Improvements in medical school wellness and career counseling: A comparison of one-onone advising to an advisory college program. Med Teach. 20I0;32(I0):e429-e435.

35. Ayala EE, Omorodion AM, Nmecha D, Winseman JS, Mason HRC. What do medical students do for self-care? A student-centered approach to well-being. Teach Learn Med. 2017;29(3):237-246.

36. Tabung FK, Steck SE, Burch JB, et al. A healthy lifestyle index is associated with reduced risk of colorectal adenomatous polyps among non-users of non-steroidal anti-inflammatory drugs HHS public access. J Primary Prevent. 2015;36(1):21-31.

37. WHO. Global Recommendations on Physical Activity for Health. Geneva, Switzerland: WHO, 2010. Available at http://apps. who.int/iris/bitstream/handle/I0665/44399/9789241599979_ eng.pdf;isessionid=DF2B4F6EF99B94IBFDE3628859E0IB89?sequ ence $=$ I. 
38. Hirshkowitz M, Whiton K, Albert SM, et al. National sleep foundation's sleep time duration recommendations: Methodology and results summary. Sleep Heal. 20I5;(I):40-43. Accessed date: 8 August 2018.

39. Lucini D, Zanuso S, Blair S, Pagani M. A simple healthy lifestyle index as a proxy of wellness: A proof of concept. Acta Diabetol. 2015;52(I):81-89.

40. Sajwani RA, Shoukat S, Raza R, et al. Knowledge and practice of healthy lifestyle and dietary habits in medical and non-medical students of Karachi, Pakistan. J Pak Med Assoc. 2009;59(9):650-655.

41. Özçakar N, Kartal M, Mert H, Güldal D. Healthy living behaviors of medical and nursing students. Int J Caring Sci. 2015;8(3):3-536.

42. Karekla $M$, Symeou $A$, Tsangari $H$, Kapsou $M$, Constantinou $M$. Smoking prevalence and tobacco exposure among adolescents in Cyprus. Eur J Public Health. 2009;19(6):655-66l.

43. Deressa W, Azazh A. Substance use and its predictors among undergraduate medical students of Addis Ababa university in Ethiopia. BMC Public Health. 2011;1:660.

44. Wattanapisit A, Fungthongcharoen K, Saengow U, Vijitpongjinda S. Physical activity among medical students in Southern Thailand: A mixed methods study. BMJ Open. 2016;6(9):e013479.

45. Steptoe A, Wardle J, Fuller R, et al. Leisure-time physical exercise: Prevalence, attitudinal correlates, and behavioral correlates among young Europeans from 2I countries. Prev Med. 1997;26(6):845-854.
46. Mohammadi G. Prevalence of seat belt and mobile phone use and road accident injuries amongst college students in Kerman, Iran. Chinese J Traumatol. 2011;14(3):165-169.

47. Wei CN, Harada K, Ueda K, Fukumoto K, Minamoto K, Ueda A. Assessment of health-promoting lifestyle profile in Japanese university students. Environ Health Prev Med. 2012;17(3):222-227.

48. Nacar M, Baykan Z, Cetinkaya F, et al. Health promoting lifestyle behaviour in medical students: A multicentre study from Turkey. Asian Pacific J Cancer Prev. 2014;15(20):8969-8974.

49. Papier K, Ahmed F, Lee P, Wiseman J. Stress and dietary behaviour among first-year university students in Australia: Sex differences. Nutrition. 2015;3I(2):324-330.

50. Cluskey M, Grobe D. College weight gain and behavior transitions: Male and female differences. J Am Diet Assoc. 2009;109(2):325329.

51. Li KK, Concepcion RY, Lee H, et al. An examination of sex differences in relation to the eating habits and nutrient intakes of university students. J Nutr Educ Behav. 2012;44(3):246-250.

52. Statistics and Research Department. Kuzey Kibris Türk Cumhuriyeti Turkish Republic of Northern Cyprus Istatistik Yilliği Statistical Yearbook 2015. Lefkosia: Statistics and Research Department, 2017. Available at http://www.devplan.org/ISTYILLIK/IST-YILLIK2015.pdf. Accessed date: 26 September 2018. 